\title{
REFLEXÕES TEÓRICAS E PRÁTICAS SOBRE A FORMAÇÃO INICIAL DE PROFESSORES NA MODALIDADE EAD
}

\author{
Luana Agostinho Tiscoski ${ }^{1}$ \\ Ricardo Luiz de Bittencourt ${ }^{2}$
}

\section{RESUMO}

A qualidade da educação depende também da qualidade da formação dos educadores, analisando as modalidades de ensino. Essa pesquisa é pautada em objetivos claros: analisar os pontos relevantes que levaram à escolha da modalidade EAD na formação inicial em Pedagogia; descrever o perfil do pedagogo na atualidade e analisar as dificuldades encontradas no exercício da prática pedagógica das professoras iniciantes. Elencou-se como teóricos principais: Hubermam (2000), Tardif (2005), Nóvoa (2009 e 2013) e Contreras (2002). Para a coleta de dados, utilizou-se entrevista semiestruturada, analisando os mesmos com base no referencial teórico construído. Diante dessa análise, há que se considerar novas metodologias, mas sem que se perca a qualidade, oportunizando reflexões desde a formação inicial.

Palavras chave: Formação de professores; Educação à Distância; Formação inicial; Pedagogia.

\section{ABSTRACT}

The quality of education also depends on the quality of educators' academic education, analyzing the teaching modalities. This research is guided by clear objectives: analyze the relevant points that led to the adoption of the distance learning modality on the initial Pedagogy academic education; describe the profile of the present pedagogue and analyze the difficulties found on while beginner teacher exert teaching practices. The main theoreticians casted were Hubermam (2000), Tardif (2005), Nóvoa (2009 and 2013) and Contreras (2002). For data gathering, semi structured interviews were used, analyzing said interviews with basis on the built theoretical referential. As a result of analysis, new methodologies must be considered, but without losing quality, providing opportunities to reflect since the initial academic education.

Key-words: Teachers' education; Distance Learning; Initial education; Pedagogy.

\section{INTRODUÇÃO}

Pensar que o processo de formação do indivíduo, desde a Educação Básica, depende também daqualidade da formação de seu educador, leva à reflexão acerca da influência que as Instituições de Ensino Superior (IES) possuem diante do Criar Educação, Criciúma, v. 6, n², julho/novembro 2017.- PPGE - UNESC 
exercício da prática docente. A formação inicial de professores possui amplas discussões considerando suas metodologias, a formação de profissionais reflexivos, entre outras esferas que o tema abrange. Nesse sentido, cabe ainda destacar a questão das modalidades de ensino, que geram discussões formais e informais. Diante desses fatores, essa pesquisa é pautada em objetivos claros: analisar os pontos relevantes que levaram à escolha da modalidade EAD na formação inicial em Pedagogia; descrever o perfil do pedagogo na atualidade e analisar as dificuldades encontradas no exercício da prática pedagógica das professoras iniciantes.

Considerando que "a formação do profissional não se encerra no momento em que o sujeito recebe o diploma da instituição formadora" (BITTENCOURT, 2008, p. 15), mas sabendo que o profissional carrega consigo muito de sua formação inicial, principalmente quando se trata de iniciantes propriamente ditos, nesse estudo se elencou como problematização a articulação entre teoria e prática na formação inicial em Pedagogia, considerando a modalidade EAD.

Para isso, primeiramente, foram reunidas bases teóricas a respeito da formação de professores, optando por utilizar uma perspectiva atual que considere o professor como profissional reflexivo, relacionando teoria e prática. Sendo assim, foram elencados como autores principais para a base teórica: Huberman (2000), Tardif (2005), Nóvoa (2009 e 2013) e Contreras (2002). Em seguida, foram coletados dados com oito professoras iniciantes formadas em Pedagogia na modalidade EAD, através de entrevista semiestruturada. Através das respostas, construiu-se uma análise com base no referencial teórico construído.

Por fim, apresentamos algumas considerações finais e finalizamos com as referências bibliográficas que deram suporte à pesquisa.

\section{A FORMAÇÃO DOCENTE SEGUNDO OS TEÓRICOS}

A reflexão sobre a qualidade do exercício docente demanda pensar sobre a formação inicial oferecida aos mesmos, visando uma construção da identidade do professor. Por isso, elencamos autores que se expressam de forma atual sobre o tema: Huberman (2000), Tardif (2005), Nóvoa (2009 e 2013) e Contreras (2002), autores que tratam da formação docente utilizando pontos de vista críticos e considerando a formação de modo geral, sem especificar uma ou outra modalidade de

Criar Educação, Criciúma, v. 6, n², julho/novembro 2017.-- PPGE - UNESC 
ensino, mas defendendo que haja uma articulação teórica e prática nessa formação, tendo em vista o perfil esperado do professor atualmente.

Sabe-se que a construção da identidade do professor passa pela construção da identidade do indivíduo, nesse sentido, Huberman (2000) trata do "Ciclo de vida profissional dos professores", que está diretamente ligado ao ciclo de vida biológico, considerando que a fase de "entrada na carreira" se dá quando o indivíduo é mais jovem e, pressupõe-se, com maior disposição para inovar e encarar novos desafios. Do mesmo modo, na fase citada como "desinvestimento" o professor encontra-se com mais idade, próximo à aposentadoria, portanto no final da carreira docente.

Nesse contexto, Tardif (2005, p.239) cita que "a epistemologia da prática profissional sustenta que é preciso estudar o conjunto dos saberes mobilizados e utilizados pelos professores em todas as suas tarefas" evidenciando que o saber docente provém de diversas esferas, sendo que esse profissional precisa estar atento ao melhor uso desses conhecimentos, advindos do meio social, profissional ou acadêmico em que o mesmo se insere, constituindo o "saber plural", que diz respeito tanto às origens quanto às aplicações destes conhecimentos. O mesmo autor traz a ideia de uma formação de qualidade, que dê suporte teórico e prático para o trabalho docente e destaca que o trabalho é uma atividade que se faz, e somente assim, podese construir saberes. Essa formação, portanto, deverá englobar teoria e prática, para que se possa desenvolver a habilidade de adequar-se a diferentes situações, tempos e espaços, utilizando os distintos saberes de acordo com as exigências postas.

Para a constituição dos saberes, Nóvoa (2013), diz que "é inútil escrever textos atrás de textos sobre o professor reflexivo se não concretizarmos a presença da profissão na formação" (NÓVOA, 2013, p. 53), em outras palavras, não se pode falar de um profissional reflexivo sem que haja uma prática a ser refletida desde a formação inicial. O autor também defende que as teorias só fazem sentido a partir do momento em que são utilizadas para enriquecer a prática e que os professores mais experientes possuem papel fundamental na formação dos professores ingressantes. Nóvoa (2009) destaca que ser professor não está ligado a uma vocação ou missão, mas sim à relação "professor-pessoa" e "pessoa-professor", já que, segundo o autor, não há como dissociar as dimensões pessoais e profissionais. Considerando que os saberes e fazeres docentes ultrapassam teorias e práticas, mas refletem também os aspectos históricos e sociais do indivíduo e da profissão, é necessário que o professor, além dos 
saberes docentes, desenvolva o autoconhecimento, visando a construção da própria identidade profissional,

No contexto de identidade, Contreras (2002) destaca que o professor, mesmo que acredite estar construindo sua prática com autonomia, ainda está preso a modelos antigos, englobando cada vez mais responsabilidades à ação docente, muitas vezes buscando mascarar um despreparo para as situações encontradas. Nesse contexto, se entende a autonomia como liberação da opressão pela profissão de professor visando a transformação do meio pela consciência crítica. Visto que a ação pedagógica é também política, considerando a formação de indivíduos críticos e autônomos diante da sociedade, é necessário também que o professor possua essas características.

Diante das colocações dos autores, percebe-se a necessidade de uma graduação que permeie essas discussões, permitindo reflexões e trocas de experiências ainda na formação inicial. Sabe-se que, mesmo a graduação avaliada como excelente em níveis de ensino, pesquisa e extensão, não dá conta de absolutamente todos os aspectos que envolvem a profissão, seja ela qual for. No entanto, é necessário sim pensar em estratégias que possibilitem a melhor qualificação desses profissionais, envolvendo tanto as bases teóricas quanto práticas. O atual cenário social demanda maior flexibilização de tempos e espaços, considerando o modo de vida desses indivíduos, bem como a inserção da tecnologia no dia a dia. Sendo assim, há possibilidade de escolha entre diferentes modalidades de ensino, conciliando a formação profissional e os demais afazeres individuais.

\section{A MODALIDADE EAD E A PEDAGOGIA}

A modalidade de ensino à distância (EAD) surgiu com um caráter emergencial, para suprir a demanda da época na educação básica, até alcançar os dias de hoje, em que está presente na graduação, visando adequação ao público-alvo e atraindo um maior número de interessados pela própria praticidade.

Temos atualmente, entre outras políticas públicas, o Plano Nacional de Formação dos Professores da Educação Básica (PARFOR), visando abranger os profissionais que atuam sem a devida formação. Os cursos são oferecidos tanto na modalidade presencial, quanto à distância, pela Universidade Aberta do Brasil (UAB), uma parceria entre o Ministério da Educação (MEC) e os estados. No site do MEC é

Criar Educação, Criciúma, v. 6, n², julho/novembro 2017.- PPGE - UNESC 
possível encontrar informações a respeito dessa formação, bem como possibilidade de inscrição do professor através da Plataforma Paulo Freire. Essa formação, portanto:

[...] abrange três situações: professores que ainda não têm formação superior (primeira licenciatura); professores já formados, mas que lecionam em área diferente daquela em que se formaram (segunda licenciatura); e bacharéis sem licenciatura, que necessitam de estudos complementares que os habilitem ao exercício do magistério. (BRASL, 2016)

A proposta de uma complementação à ação prática já existente é satisfatória, tendo em vista que o profissional já possui conhecimentos práticos e uma noção teórica adquirida nas formações complementares oferecidas pelas próprias escolas ou órgãos responsáveis. Nesses casos, a modalidade EAD vem ao encontro desses profissionais que necessitam de uma formação adequada e uma base teórica mais sólida.

A questão do acesso à graduação também não pode ser esquecida, tendo em vista o modo de vida atual, em que os seres humanos estão cada dia mais atarefados e, por isso mesmo, mais propensos a optar pela praticidade.

Não se pode, portanto, negar a necessidade dessa flexibilização na formação de professores. Porém, há que se pensar na qualidade oferecida diante da popularização da modalidade EAD, sendo procurada como formação inicial por indivíduos que nunca tiveram contato com os fazeres pedagógicos. Sendo assim, as oito entrevistadas foram questionadas sobre os motivos que as levaram à escolha pela modalidade EAD, a organização didático-pedagógica do curso e os desafios encontrados na prática, diante da formação inicial.

\section{METODOLOGIA E ANÁLISE DE DADOS}

Após a organização do referencial teórico supracitado, aplicou-se uma entrevista semiestruturada, ou seja, flexível de acordo com as respostas das entrevistadas, sendo que as mesmas foram gravadas e, em seguida, transcritas para um melhor aproveitamento. Nessa coleta de dados, foram entrevistadas oito professoras iniciantes, formadas em Pedagogia na modalidade EAD e que atuam na Educação Infantil, visando perceber essa articulação teórica e prática em sua formação inicial, bem como as dificuldades enfrentadas diante do confronto com a realidade da sala de aula. A ênfase em profissionais da Educação Infantil se deu em

Criar Educação, Criciúma, v. 6, n², julho/novembro 2017.- PPGE - UNESC 
função da maior autonomia diante das exigências para essa faixa etária, sendo que no Ensino Fundamental muitos estão presos a modelos de livros didáticos, possibilitando pouca autonomia do professor. Os dados foram analisados com base no referencial teórico construído, relacionando as ideias dos autores citados com as afirmações das entrevistadas.

$\mathrm{Na}$ seguinte apresentação e análise dos dados, os sujeitos da pesquisa são identificados por S1, S2, S3 e assim por diante, visando preservar a identidade dos mesmos.

A escolha pela modalidade de ensino na formação inicial é o primeiro passo na vida profissional, visto que é nesse período que o indivíduo passa a se identificar, ou não, com a profissão escolhida. Quanto às motivações que levaram à escolha da modalidade EAD, as respostas das entrevistadas vão ao encontro dessa perspectiva do ensino mais acessível, considerando a comodidade e o valor das mensalidades. S2, além desses aspectos, destaca: "Eu já tinha feito o magistério. No magistério eu aprendi tudo... então, para mim, foi bem completo. Eu fiz à distância mais para complementar e também porque eu não tinha condições de pagar".

A resposta de $S 2$ reforça a ideia da modalidade EAD como capacitação em serviço, fornecendo conhecimentos teóricos a profissionais já familiarizados com os aspectos práticos. É necessário, diante das possibilidades, refletir sobre a qualidade dessa formação inicial em Pedagogia em que a troca de experiências fica defasada, diante de um menor tempo de convívio do professor com seus alunos na graduação. Desse modo, de acordo comBittencourt (2008), há uma descaracterização do processo educativo, que deveria promover a aproximação, e não o distanciamento entre professor e aluno. Não se trata de negar a importância dessa modalidade, mas de pensar sobre essa aceleração e precarização do processo, contribuindo para a desvalorização do professor. Lembrando que "também cursos na modalidade presencial podem ser precarizados, principalmente quando a formação de professores passa a ser um grande negócio" (BITTENCOURT 2008, p.47), gerando competição entre as IES que valorizam mais a quantidade do que a qualidade dos profissionais formados.

Uma formação de qualidade, de acordo com Tardif (2005), tem como função fornecer aos alunos saberes teóricos e técnicos para o trabalho. Sendo assim, as entrevistadas foram questionadas quanto às abordagens dos eixos que compõem a Educação Infantil, de acordo com a Proposta Curricular de 1998, considerando a área de atuação das mesmas. S7 afirma não lembrar o Criar Educação, Criciúma, v. 6, n², julho/novembro 2017.-- PPGE - UNESC 
nome das disciplinas, já S6, embora também cite esse esquecimento, diz que todas as disciplinas abordam os temas: "Por exemplo, quando foi falado da Literatura na Educação Infantil, foi falado desse negócio de contar histórias, com música, brincando com eles. Então, eu acho que foram todas que abordaram". S3 também afirmou que "Todas as disciplinas de minha graduação foram voltadas aos eixos, não existe uma específica, mas uma aborda com mais ênfase e outras foram mais superficiais".

S4 tem sua graduação voltada às séries iniciais, logo, afirma que "apareceu pouco sobre a Educação Infantil, mas tínhamos Sociologia da Educação, Didática do Professor e Educação Inclusiva, onde falavam um pouco sobre essas disciplinas, porém mais voltado às séries iniciais".

$\mathrm{S1}$, S2, S5 e S8 citaram as disciplinas voltadas à didática e à Educação Infantil mais especificamente:

\footnotetext{
Linguagem: Psicologia da educação e aprendizagem, Literatura e também os Temas transversais.

Brincadeira: Cultura popular brasileira, Lúdico e musicalização

Interações: Lúdico e musicalização, Literatura infantil, Psicomotricidade e diria também Educação Inclusiva

Organização espaço-temporal: Psicomotricidade (S1).

Lúdico e música [...] Tem também a disciplina que fala mesmo da Educação Infantil, porque tem aquela disciplina que é das Séries Iniciais e tem a de Educação Infantil, que aborda bastante esses eixos. (S2).

Comunicação e Linguagem, Ludicidade e Educação, Ensino de Natureza e Sociedade na Educação Infantil e Organização e Didática na Educação Infantil (S5).

As mais específicas da Educação Infantil, aquelas mais focadas em trabalhar com crianças de zero a seis anos. Mas eu lembro, no meu caderno, a Didática... A Didática fala muito sobre isso, bem específico isso dos jogos, das brincadeiras, como tem que ser a brincadeira orientada, a brincadeira livre, nos jogos, como tem que cobrar as regras, se é um jogo mais livre... Na parte da Didática (S8).
}

Como já mencionado, o conhecimento teórico é uma das bases do saber docente e, conforme as respostas das entrevistadas, se percebe a preocupação das IES diante desses saberes, sendo que, embora algumas tenham demonstrado esquecimento quanto à nomenclatura das disciplinas, as que responderam puderam citar mais de uma disciplina envolvendo esses aspectos, o que pressupõe uma abordagem, ao menos teórica, dos conteúdos na modalidade EAD. 
Seguindo a linha da entrevista, buscou-se compreender a visão dos sujeitos acerca da articulação teórica e prática em sua formação inicial em Pedagogia, ao que S2, S3, S6 e S7 afirmam, respectivamente:

[...] Teoria é dentro da sala de aula e a prática, para associar, é a questão dos estágios mesmo (S2).

A teoria é o que eu estudo, a prática é quando trabalhamos no dia a dia. No curso não fazemos aulas práticas (S3).

Quando eu estava estudando, na teoria era bem bonitinho e maravilhoso... Quando a gente vai para a sala de aula, seja como estagiária, auxiliar ou professora, é bem diferente e eu tive um pouco de dificuldade quando iniciei, porque iniciei como estagiária de duas crianças especiais e a gente aprendeu que na teoria é tudo bonitinho e na realidade não é assim (S6).

Não tinham aulas práticas, era só teoria, papel, livro... Nem a professora, o tutor da sala, não falava muito sobre o assunto daquela aula, não trazia atividade para a gente fazer, relacionada àquele assunto, então isso deixou muito a desejar. Prática com teoria não tinha nenhum vínculo, era só a teoria mesmo (S7).

Tais respostas reafirmam um conceito de que na sala de aula ocorre apenas a teoria e que a prática se dá no momento dos estágios, o que contradiz as discussões acerca da articulação entre teoria e prática na formação inicial, remetendo ao profissional reflexivo. Esse aspecto leva a refletir sobre a influência dessa dissociação teórica e prática quando os referidos profissionais aplicarem seus planejamentos nas salas de aula da Educação Básica, sendo que, para um bom ensino é necessário antes que o professor possua os conhecimentos internalizados através de ampla reflexão.

É de extrema importância uma formação que proporcione valorização do saber docente através de uma "reflexão sobre a prática e uma teorização da experiência" (NÓVOA, 2010, p.54), visto que ensinar é percebido como tarefa fácil diante da sociedade, o que acaba por desvalorizar a função daquele que ensina. Quanto a isso, Shaw (1900, apud NÓVOA, 2010, p. 54) afirma que "os homens são sábios na proporção não da sua experiência, mas da sua capacidade para pensar a experiência", o que reforça a ideia de um profissional que aprende através da articulação indissociável entre teoria e prática, que deve ocorrer simultaneamente e não de forma fragmentada.

S1, S4 e S5 citam, além dos estágios, as socializações em sala de aula:

Criar Educação, Criciúma, v. 6, n², julho/novembro 2017.- PPGE - UNESC 
A teoria nos é apresentada pelo professor tutor externo em sala de aula e reflete em três avaliações. A prática é através dos estágios e apresentações de trabalho de final de semestre, os chamados Papers. [...] Os Papers, a professora dá um tema pra cada grupo e, dentro desse tema, a gente precisa apresentar uma parte teórica e uma parte prática (S1).

Foram realizadas juntas, fazíamos apresentações em sala de aula (S4).

A teoria e a prática acontecem em sala de aula, brinquedoteca e laboratórios de informática e também nos estágios supervisionados (S5).

Enquanto S8 traz que:

\begin{abstract}
Quando as práticas eram voltadas para a criança, principalmente literatura, ela trazia uns livros e colocava disponível e perguntava quem gostaria de contar uma história, aí conforme a gente contava a história, ela ia determinando: "agora você vai fazer uma voz fina, agora você vai fazer uma voz grossa...". Domínio da explicação do caderno em si, às vezes deixava um pouquinho a desejar, mas essa parte do concreto, da construção, da dinâmica, da brincadeira... Tinha esse momento na sala, todo encontro era feito alguma coisa. E a experiência, por exemplo, quando alguma criança comentava alguma coisa... Na minha turma, na época, a gente estava trabalhando a questão de preservar as árvores, então ela disse: "eu quero uma experiência do que vocês estão fazendo lá na sua sala" e foi quando ela fez conosco um miniterrário, bem no começo e no final da faculdade ele estava lá, perfeito, dentro da garrafa PET. Minha professora proporcionava bastante esses momentos.
\end{abstract}

Diante dessas informações, surge uma nova visão dos cursos na modalidade EAD, considerando a professora responsável pela turma, chamada de tutora pelos acadêmicos, visto que S8 cita a influência da mesma proporcionando as práticas e construções, tanto individuais quanto coletivas, em sala de aula, enriquecendo o processo. Os trabalhos citados também pressupõem pesquisa, além do que está posto nos livros, oportunizando um aprofundamento no assunto para socialização com o grupo.

Pensando na influência da chamada tutora há que se refletir também sobre a carência de profissionais especializados para ministrar as aulas às acadêmicas e abordar os temas de forma mais clara os temas em questão, tendo em vista que apenas um profissional atende à todas as disciplinas do curso. 


\section{CRIAR EDUCAÇÃO \\ Revista do Programa de Pós-Graduação em Educação - UNESC}

Percebendo esses aspectos, as entrevistadas também responderam

acerca dos desafios encontrados diante do confronto entre os conhecimentos

adquiridos e a realidade da sala de aula sendo que S2 e S5 responderam que não tiveram dificuldades, a primeira se justificou pelo fato de ter a formação no magistério. Já S4 afirma que, "no início, o medo, até hoje a gente tem um pouco, mas foi indo, com as orientações do lugar onde se trabalha". S3 afirma que sua dificuldade foi em "como aplicar, se minha prática estava correta".

S1, por sua vez, alega que:

Um dos grandes desafios enfrentados é acabar com a ideia de um modelo único de ensino. É necessário estar atentos às mudanças que estão sendo exigidas do profissional da educação e muitas vezes lidamos com colegas de trabalho que não pensam assim e também não aceitam isso.

S6, S7 e S8 comentaram sobre a metodologia diferenciada do local onde trabalham e que, no início tiveram dificuldades em aplicá-la, pois a mesma é diferente do que aprenderam na IES ou quando exerciam a função de auxiliar em outro local:

Quando eu comecei aqui na creche, e a metodologia daqui é diferente da metodologia do município, eu pensei que não iria dar conta. Depois comecei a trabalhar no município e pensei "A dificuldade não é aqui, a dificuldade é lá", pois lá é tudo largado. Então a metodologia daqui é um pouco mais "puxada", mas é mais prazeroso trabalhar aqui e a minha única dificuldade foi nisso, pois como auxiliar a gente via que só auxiliava e as professoras faziam mais ou menos, e aqui não, a gente entende o que a gente faz e parece que é melhor, pois são as crianças que produzem (S6).

Quando eu trabalhava de auxiliar, sempre peguei professoras bem boas, aprendi bastante com elas. Eu não fazia o trabalho delas, eu auxiliava, mas estava sempre por dentro do que elas estavam fazendo, sempre querendo ajudar, para aprender também. Mas, quando eu vim para cá, tive essa dificuldade por ser diferente da rede, mas depois a gente vê que a gente aprende junto e isso favorece nosso crescimento e vemos realmente o que é melhor ou não. Foi mais isso, a mudança de ambiente (S7).

Como professora, passei por essa dificuldade de troca e como coordenadora eu observo isso nas meninas, de pensar que não vão conseguir, porque é muito Xerox e aqui é muito a produção da criança, a criança tem que produzir. As nossas salas não têm nada de EVA, tem os painéis, mas tudo é construído com eles, tudo tem a mãozinha deles [...] (S8).

Criar Educação, Criciúma, v. 6, n², julho/novembro 2017.- PPGE - UNESC 
As professoras de nossa pesquisa encontram-se na fase de "entrada na carreira", descrita por Huberman (2000) como um momento em que estão motivadas a exercer a profissão, ao mesmo tempo em que confrontam suas expectativas com a realidade encontrada, o que justifica a insegurança inicial, citada por algumas entrevistadas, bem como o fato de querer "romper" com os modelos impostos.

Conforme as afirmações das entrevistadas, se constata que cada ambiente de trabalho possui sua cultura, exigindo do profissional um amplo conhecimento sobre diferentes métodos, visando a construção da identidade desse profissional, bem como sua adequação ao ambiente em que se encontra. À essa percepção pode-se relacionar o conceito de Tardif (20065), no sentido de que a prática profissional nunca traduz fielmente os conhecimentos universitários, visto que estes são construídos em torno de generalizações, enquanto o saber profissional requer uma adequação ao ambiente em que se está inserido.

Não se pretende, no entanto, negar a competência das profissionais entrevistadas, mas sim refletir sobre a influência da formação inicial no ingresso da carreira docente, percebendo que alguns desafios poderiam ser amenizados diante de metodologias em que a teoria e a prática, bem como reflexões sobre as mesmas fossem abordadas com maior ênfase.

\section{CONSIDERAÇÕES FINAIS}

O tema abordado é instigante pelo seu próprio teor, de certa forma, polêmico e se considerou tratar do mesmo de forma extremamente ética e, ao mesmo tempo, crítica, sem desmerecer a qualidade dos profissionais em questão, percebendo que a formação inicial não é a única determinante do perfil profissional docente.

A análise faz perceber que a modalidade EAD tem atraído um maior público por sua comodidade e valor, embora haja certa dissociação entre teoria e prática nos cursos de Pedagogia EAD. Considerando o que se reflete sobre a formação de professores, que devem atuar como profissionais políticos, formando indivíduos críticos e reflexivos diante da sociedade, há que se pensar nessa formação do profissional, que muitas vezesnão oportuniza espaços de discussão para que o

Criar Educação, Criciúma, v. 6, n², julho/novembro 2017.- PPGE - UNESC 
mesmo desenvolva tais características, ou seja, dificilmente conseguirá instigar seus alunos para essa ação.

Deve-se considerar sim o investimento em novas alternativas, mas sem desconsiderar a qualidade nessa formação inicial, para que se obtenha profissionais realmente qualificados.

Uma prática de qualidade só é possível a partir de uma base teórica sólida, compreendida na reflexão da prática, formando um ciclo de formação e transformação do profissional docente.

A pesquisa não se encerra em si própria, visto que cabe a cada individuo lançar seu olhar crítico também sobre a realidade. A mesma serve de ponto de partida à novas discussões, visando a construção de uma formação inicial em Pedagogia de qualidade, onde haja, de fato, uma articulação teórica e prática sem dissociação, sendo que ambas enriquecem-se mutuamente. Embora haja ampla gama de discussões a esse respeito, ainda há muito o que refletir para atingir os objetivos de uma educação de qualidade.

\section{REFERÊNCIAS:}

BITTENCOURT, Ricardo Luiz de. Formação de professores em nível de graduação na modalidade EAD.: O caso da Pedagogia da UDESC - Pólo de Criciúma - SC. 2008. 254 f. Tese (Doutorado) - Curso de Doutorado em Educação, Universidade Federal do Rio Grande do Sul. Faculdade de Educação. Programa de Pós-graduação em Educação, Porto Alegre, 2008.

\section{MINISTÉRIO DA EDUCAÇÃO. Plano Nacional de Formação de Professores} da Educação Básica.Disponível em: <http://portal.mec.gov.br/plano-nacionalde-formacao-de-professores>. Acesso em: 20 jan. 2016.

CONTRERAS, José. Autonomia de professores. São Paulo: Cortez, 2002.

HUBERMAN, Michäel. O ciclo de vida profissional dos professores. In: NÓVOA, António (Org.). Vidas de professores. 2. ed. Portugal: Porto, 2000. p. 31-61.

NÓVOA, Antonio. Para uma formação de professores construída dentro da profissão. Revista de Educación, p. 203-218, set./dez. 2009. Disponível em: <http://www.revistaeducacion.educacion.es/re350/re350_09por.pdf>. Acesso em: 27 jul. 2015.

. Três bases para um novo modelo de formação. Gestão Escolar, p.5255, Ago/set 2013.

Criar Educação, Criciúma, v. 6, n², julho/novembro 2017.-- PPGE - UNESC 
TARDIF, Maurice. Saberes docentes e formação profissional. Petrópolis, Rj: Vozes, 2005. 